\title{
CORRESPONDENCE
}

\section{SynTarget: an online tool to test the synergetic effect of genes on survival outcome in cancer}

\author{
Cell Death and Differentiation (2016) 23, 912; doi:10.1038/cdd.2016.12; published online 26 February 2016
}

\section{Dear Editor,}

The identification of target combinations with synergistic effects on cancer is at the leading edge of modern cancer research, especially for the development of combined anticancer therapies. ${ }^{1}$ However, at present, the basis for selection of beneficial target combinations commonly relies on expert opinion without any systematic rationale. The development of high-throughput technologies has led to the availability of large-scale clinical gene expression data sets. ${ }^{2-4}$ Mining of these data sets for identification of gene combinations with synergetic effects on survival outcome in cancer could provide a systematic rationale for the identification of target combinations with potential therapeutic synergy.

Multiple online tools have been developed recently to assess the relationship between expression of a single gene and clinical outcome across a variety of cancers. ${ }^{5,6}$ Here we present SynTarget, the first tool able to test the cumulative effect of two genes on survival outcome and, therefore, can identify gene pairs with synergistic effects. At present, SynTarget is based on 15 large-scale gene expression data sets covering eight different cancers with the possibility to select clinically important subtypes (i.e., triple-negative, p53 mutated cancers, K-ras mutated cancers etc.). On submission, the user selects a specific cancer data set and subtype and specifies two genes. Patients in the selected data set (subtype) are split into four groups with respect to the expression of the specified genes (high - high, high - low, low - high and low - low). Next, each group is tested versus other samples to find any statistical differences in survival outcome (i.e., high - high versus others, high - low versus others and so on). This information is accompanied by individual-gene survival effects in order to understand the degree of gene synergy.

Among other drug classes, immunotherapeutic agents have enormous potential for synergistic combinations. ${ }^{1}$ Triplenegative breast cancer is the subtype with the worst prognosis among all breast cancer subtypes, with currently no known molecular targets. ${ }^{7}$ We used SynTarget to search cell surface genes with the synergistic potential on survival, whose high expression leads to significantly negative prognosis. For example, ADAM9 is a membrane-anchored protein and has been implicated in a variety of biological processes, as well as being involved in cancer metastasis. $\mathrm{RC} 3 \mathrm{H} 2$ is a membraneassociated nucleic acid-binding protein. High expression of both genes individually was slightly negatively associated ( $P$-values $\sim 0.07$ and 0.04$)$ with survival in triple-negative patients from the METABRIC data set. ${ }^{3}$ The subgroup of triplenegative patients where both genes are highly expressed has a significantly negative shift $(P$-value $<6 e-05)$ in survival, in comparison with other patients (see Supplementary Materials for details). Therefore, SynTarget provides statistical evidence that high expression of both $\mathrm{RC} 3 \mathrm{H} 2$ and ADAM9 synergistically affects survival of patients with triple-negative breast cancer.

In summary, SynTarget supports the need of biomedical researchers to estimate the synergy of gene expression on survival of cancer patients. To our knowledge this is a first tool of this kind and, as shown by several examples (see Supplementary Materials), SynTarget can be used for fast validation of the clinical synergy for two genes. SynTarget is incorporated into BioProfiling. de, an analytical portal for high-throughput cell biology, ${ }^{8}$ and is freely available at http://www.bioprofiling.de/synergy2G.

\section{Conflict of Interest}

The authors declare no conflict of interest.

Acknowledgements. This work was supported by the UK Medical Research Council (MRC) and fundamental research program of the Russian State Academies of Sciences.

\section{Amelio ${ }^{1}$, PO Tsvetkov ${ }^{2,3}$, RA Knight ${ }^{1}$, A Lisitsa ${ }^{4}$, G Melino ${ }^{1,5,6}$ and AV Antonov ${ }^{*, 1,6}$}

${ }^{1}$ Medical Research Council, Toxicology Unit, Leicester University, Lancaster Road, P.O. Box 138, Leicester, UK;

2 Aix-Marseille Université, Inserm, CRO2 UMR S 911, Faculté de Pharmacie, Marseille, France;

3 Institute of General Pathology and Pathophysiology, RAMS, 125315 Moscow, Russia;

${ }^{4}$ Institute of Biomedical Chemistry, Russian Academy of Medical Sciences, Pogodinskaya Street, Moscow, Russia;

5 Department of Experimental Medicine and Surgery, University of Rome "Tor Vergata", Via Montpellier 1, 00133 Rome, Italy and

6 Institute of Cytology, Saint-Petersburg 194064, Russia

* Corresponding authors: AV Antonov, Medical Research Council, Toxicology Unit, Leicester University, Hodgkin Building, Lancaster Road, P.O. Box 138, Leicester LE1 9HN, Leicestershire, UK. Tel: +44 (0)116 252 5562; Fax: +44 (0)116 252 5598; E-mail: aa668@le.ac.uk

\footnotetext{
1. Melero I et al. Nat Rev Cancer 2015; 15: 457-472.

2. Cancer Genome Atlas Network. Nature 2012; 487: 330-337.

3. Curtis C et al. Nature 2012; 486: 346-352.

4. Amelio I et al. Cell Death Dis 2014; 5: e1051.

5. Antonov AV et al. Oncogene 2014; 33: 1621-1628.

6. Gyorffy B et al. Breast Cancer Res Treat 2010; 123: 725-731.

7. Crown J, O'Shaughnessy J, Gulio G. Ann Oncol 2012; 23: vi56-vi65.

8. Antonov AV. Nucleic Acids Res 2011; 39: W323-W327.
}

(c) (1) (2)(2) This work is licensed under a Creative Commons (c) ${ }_{\text {BY }}{ }_{\text {NC }}$ SA Attribution-NonCommercial-ShareAlike 4.0 International License. The images or other third party material in this article are included in the article's Creative Commons license, unless indicated otherwise in the credit line; if the material is not included under the Creative Commons license, users will need to obtain permission from the license holder to reproduce the material. To view a copy of this license, visit http://creativecommons.org/licenses/by-nc-sa/4.0/ 